\title{
Relações de subordinação em repúblicas universitárias de Ouro Preto
}

\section{Subordination relationships in university republics of Ouro Preto}

\author{
Carolina Macha Saraiva de Albuquerque Maranhão' ${ }^{1}$, Talita Almeida Fernandes², \\ André Felipe Vieira Colares ${ }^{3}$
}

\section{Resumo}

O objetivo deste trabalho é analisar, à luz das contribuições se Georg Simmel, como as repúblicas universitárias na cidade de Ouro Preto se organizam a partir das relações de poder e subordinação entre os alunos calouros e os alunos veteranos. Tradicionalmente denominados por "bixos", em Ouro Preto, os calouros passam por "batalhas" para serem aceitos em repúblicas, tanto particulares quanto federais. O processo de coleta de dados deu-se por meio da triangulação das seguintes técnicas: entrevistas semiestruturadas realizadas com quatorze acadêmicos de repúblicas federais, na cidade de Ouro Preto; observação não participante e análise documental. Os dados coletados foram tratados com base na técnica de análise de conteúdo (BARDIN, 1977). O que se observa é que, diferentemente das organizações empresariais, as relações de subordinação (e poder) não se fazem tão descompensadas talvez, pelo fluxo constante das repúblicas e a rotatividade de seus membros.

Palavras-chave: Repúblicas universitárias de Ouro Preto. Relações de poder. Subordinação. Georg Simmel.

\begin{abstract}
The aim of this work is to analyze, based on Georg Simmel's contributions, how the University in the city republics of Ouro Preto are organized from the relations of power and subordination among freshmen students and veteran students. Traditionally denominated by "mobs", in Ouro Preto, the freshmen go through "battles" to be accepted in particular as both federal republics. The data collection process took place through triangulation of the following techniques: semi-structured interviews carried out with fourteen academic federal republics, in the city of Ouro Preto; non-participant observation and documentary analysis. The data collected were treated based on content analysis technique (BARDIN, 1977). What is observed is that, unlike the business organizations, relationships of subordination (and power) are not so unbalanced - perhaps by the steady stream of Republics and the turnover of its members.
\end{abstract}

Keywords: University of Ouro Preto Republics. Power relations. Subordination. Georg Simmel.

1 Doutora em Administração pela Universidade Federal de Minas Gerais, MG. Professora Adjunta da Universidade Federal de Ouro Preto. Coordenadora do Observatório C.A.F.E. - Observatório em Crítica, Formação e Ensino em Administração. E-mail: carola.maranhao@gmail.com

2 Mestranda em Administração pela Universidade Federal do Espírito Santo (UFES).

3 Mestre em Administração pela Universidade Federal de Minas Gerais. André Felipe Vieira Colares. Professor Substituto de Administração na Universidade Federal de Ouro Preto. 


\section{Introdução}

As possibilidades de acesso ao ensino superior no Brasil acabam por facilitar que alunos das mais diversas regiões possam ingressar em universidades diferentes daquelas localizadas próximo às suas cidades. No caso de Mariana e Ouro Preto, cidades que sediam os principais campi da Universidade Federal de Ouro Preto, o que se pode perceber é um grande fluxo de universitários de fora que vão para a cidade estudar; e consequentemente, fixam moradia durante o percurso da graduação. Surge daí a principal utilidade das moradias estudantis com baixo custo e que atendam às necessidades dos estudantes.

A demanda de alunos por moradias universitárias dentro destas universidades, de atração regional e às vezes nacional, nem sempre é coberta por toda a Universidade; devido às limitações de espaço, organização e até mesmo financeira. E, em se tratando de um percurso acadêmico de no mínimo quatro anos, parte dos universitários e seus familiares acabam por optar e incentivar à formação das denominadas repúblicas universitárias. Entre os ideais de vida coletiva, além do compartilhamento financeiro e de experiências, observa-se também como um impulsionador, o fator sociação, proposto por Simmel (1983, 2006).

Portanto, debruçar-se sobre as repúblicas universitárias torna-se interessante ao ver neste tipo de organização as características de organizações empresariais como recrutamento, gestão de recursos, divisão do trabalho, relações de poder, etc. Garrido e Mercuri (2013) apontam sobre a incipiência dos estudos nacionais sobre moradias estudantis e, consequentemente, as repúblicas universitárias enquanto uma modalidade também de moradias. Os autores ainda apontam que pouco se pesquisa sobre este espaço enquanto peça importante na constituição dos indivíduos.

O objetivo deste trabalho é analisar, à luz das contribuições se Georg Simmel, como as repúblicas universitárias na cidade de Ouro Preto se organizam a partir das relações de poder e subordinação entre os alunos calouros e os alunos veteranos. Tradicionalmente denominados por "bixos", os calouros nas cidades de Mariana e Ouro Preto passam por "batalhas" para serem aceitos em repúblicas, tanto particulares quanto federais; o que incita a necessidade de se refletir sobre essa relação entre universitários.

Entre os aportes teóricos para validar a discussão, busca-se trazer a discussão desenvolvida por Simmel (1983) acerca de relações e do processo de subordinação e poder, que se dão por meio de conceitos tais como: sociação e sociabilidade. De acordo com Simmel $(1983,2006)$ a sociação é identificada pela interação dos interesses individuais dos sujeitos a partir do momento em que tais interesses se tornam coletivos. Uma forma de sociação é a sociabilidade que, conforme Simmel (2006) corresponde a uma forma lúdica de sociação, um espaço onde a interação sai da formalidade e passa para o nível da informalidade, da brincadeira e da conversa.

Observa-se que a discussão gira em torno das relações estabelecidas nas repúblicas universitárias sob um espectro de desproporcionalidade dos processos de subordinação (e poder) entre calouros e veteranos e a consequente subordinação dos primeiros.

Visando atingir os objetivos deste trabalho, após esta breve introdução será apresentada uma seção teórica sobre organização das repúblicas universitárias e o processo de sociação; posteriormente uma seção teórica sobre as relações de poder e subordinação presentes nas repúblicas universitárias; logo após, a metodologia desenvolvida e como se deu o organizar da pesquisa; em sequência serão apresentadas as análises dos dados coletados com resultados e discussão e, por fim as conclusões da presente pesquisa. 
As Repúblicas Estudantis de Ouro Preto: Um Pouco da História

As repúblicas estudantis de Ouro Preto sempre foram importantes para a conservação do patrimônio histórico da cidade, minimizando os gastos públicos com a conservação e manutenção do patrimônio. Segundo Machado (2014, p. 11), “os investimentos públicos com a compra de casas para repúblicas é datado de 1958, quando a Escola de Minas cedeu um prédio que adquirira em 1953 para instalar a República Castelo dos Nobres". Sobre as repúblicas estudantis federais de Ouro Preto, a UFOP afirma que:

são os imóveis que a Universidade cede aos alunos para a moradia estudantil. Em Ouro Preto são 58 repúblicas. Elas se localizam no entorno do campus Morro do Cruzeiro e espalhadas pelo centro histórico de Ouro Preto. Às moradias é assegurada a autogestão, em que cada casa tem seu regimento interno. Assim sendo, cada moradia tem um critério de seleção próprio que dura três meses, e no qual é avaliado o espírito de solidariedade e senso de comunidade. (UNIVERSIDADE FEDERAL DE OURO PRETO, 2015)

As repúblicas são um grande patrimônio da UFOP. Foi a partir das dificuldades de permanência encontradas por estudantes em Ouro Preto que os alunos se organizaram e as repúblicas foram formadas. Gradativamente os alunos aprenderam a estruturar as repúblicas enquanto organizações. Assim a vida republicana foi marcada pela divisão das tarefas e atribuição de responsabilidades a cada morador. Machado (2014, p. 12) completa que "nas repúblicas, para se morar, o calouro precisa se pôrr à prova, tanto em sua capacidade e destreza para auxiliar na manutenção da casa como da presença de espírito, ao atribuir valor à amizade. Enfim, preocupação com os demais membros".

Após a transferência da capital de Minas Gerais para Belo Horizonte, Ouro Preto foi despovoada e "parecia, de uma hora para outra, se tornar o símbolo do atraso, da Monarquia e da anti-modernização perante à sua tradição" (MACHADO, 2014, p. 15). Entretanto, muitos imóveis tornaram-se disponíveis e vários deles foram ocupados por estudantes ou cedidos para eles. A desvalorização imobiliária foi tanta que muitas vezes a família preferia não quitar os impostos e deixar que a casa se tornasse propriedade do governo.

Nesta mesma época, Machado (2014) afirma que Ouro Preto atraía muitos estudantes de todos os estados do Brasil pois a cidade proporcionava uma boa escola e um local com condições agradáveis para se viver e estudar. Segundo o autor, como as estradas só surgiram em 1938, levava-se mais de 5 horas de Ouro Preto para Belo Horizonte, além disso, a comunicação era ineficiente e a maior parte dos estudantes ficava em Ouro Preto o ano todo e só voltava para sua casa nas férias mais longas. Havia, também, as comemorações como o 12 de Outubro, festejada até hoje. A Festa do 12, como é chamada, reúne ex-alunos, alunos e professores.

Machado (2014) ressalta que o aumento do número de estudantes na mesma casa tornou necessária a criação de regras. Havia, segundo o autor, um livro com a descrição de todas as despesas da casa, controladas pelo presidente do mês e divididas igualmente aos moradores. Até a fundação do restaurante universitário, em 1959, as refeições eram preparadas e servidas nas repúblicas e o convívio era cada vez mais intenso, uma vez que compartilhar por vários anos as expectativas, tristezas e alegrias unia os moradores com fortes laços de amizade e espírito de família (MACHADO, 2014).

Desde 1938, o Diretório Acadêmico da Escola de Minas de Ouro Preto vislumbrava a criação de uma entidade assistencial e procurava apoio junto à Casa do Estudante do Brasil (CEB). Entretanto, com a criação da União Nacional dos Estudantes (UNE), a CEB perdera sua força no cenário estudantil (MACHADO, 2014). Anos depois, em 1946, foi 
criada a Casa do Estudante de Ouro Preto (CEOP), que visava promover proteção e beneficência aos estudantes de Ouro Preto. Machado (2014) ressalta que esta entidade recebia recursos públicos e privados, tais como do Consórcio Administrativo de Empresas de Mineração (CADEM); St. John de Rey Mining Company Limited; Companhia Minas da Passagem; Mineração Geral do Brasil; Companhia Geral de Minas, entre outros. Já em 1953, após a criação da Casa do Estudante da Escola de Minas, o autor completa que tal instituição construiu repúblicas tradicionais dos estudantes de Ouro Preto e reformou prédios antigos. As repúblicas atendidas pela Casa do Estudante eram particulares e conquistaram suas casas juntando-se aos moradores de outras repúblicas e participando de sorteios para a definição das casas (UNIVERSIDADE FEDERAL DE OURO PRETO, 2015).

Após a definição da localização das repúblicas, coube aos estudantes ocupar as casas e, de alguma forma, organizar e transformar os lugares que lhes foram cedidos em algo mais do que lugares como configurações estáticas, mas em espaços de vivência, ou ainda, conforme a definição de Certeau (1994): o espaço como um lugar praticado.

\section{Moradia Universitária: o Processo de Aceitação}

Ao longo dos anos, o processo de ingresso e aceitação do estudante como morador em repúblicas universitárias vem sendo severamente criticado devido, em algumas situações, perpassar por questões de humilhação vinculadas aos trotes. Outras vezes, as repúblicas são vistas apenas como estruturas físicas que agregam estudantes durante a graduação, reificando a opinião de muitas pessoas que defendem a adoção de critérios socioeconômicos para o ingresso dos estudantes em repúblicas federais.

Contudo, deve-se observar que para o bom funcionamento das repúblicas existe a necessidade de que os moradores sigam algumas regras e estejam em constante vigilância dentro das casas cedidas pela universidade. Daí a importância de pessoas que respondam umas às outras hierarquicamente e que possuam afinidade para conviver os intensos anos da graduação. A Pró-reitoria de Assuntos Comunitários eEstudantis(PRACE/UFOP) regulamenta e controla o ingresso de novos estudantes, além de possuir o Estatuto das Repúblicas Estudantis que especifica o que são essas moradias, seus objetivos, direitos, deveres, e dá às repúblicas o direito de possuir um regimento interno, como consta no documento intitulado Estatuto das Repúblicas Estudantis:

"Art.12 Cabe aos moradores de cada Residência adotar as normas complementares necessárias ao adequado funcionamento da casa".

A REFOP também consta no documento e sua mediação é marcada por meio da necessidade de um regimento que atenda às necessidades e demandas específicas das repúblicas associadas:

"Art.13 A REFOP, mencionada no presente Estatuto, é formada por representantes de todas as Residências Estudantis da UFOP e é regulada por Estatuto e Regimento próprio".

A organização das repúblicas tem início com a hierarquia interna, que deve manter o bom funcionamento da casa e responder à Associação das Repúblicas Federais de Ouro Preto (REFOP) e à PRACE. A REFOP é uma articulação dos alunos e ex-alunos das repúblicas estudantis federais da universidade Federal de Ouro Preto. Responsável pela organização das repúblicas federais, trabalha juntamente com a PRACE de forma que as organizações republicanas estejam aptas a prestar contas para a Reitoria da UFOP e Ministério Público.

Algumas obrigações das repúblicas estudantis federais de Ouro Preto são a elaboração do regimento interno para a apreciação da PRACE e publicação nos canais de divulgação da UFOP; o estabelecimento do tempo de permanência do morador na residência estudantil; e a exclusão do 
morador que obtiver o coeficiente de rendimento semestral inferior a 5,0 por mais de dois períodos consecutivos. Além disso, é vedada a entrada de menores sem a prévia autorização dos responsáveis. Essas e outras obrigações são executadas pelos moradores das repúblicas universitárias ouropretanas e supervisionadas pela PRACE.

Quanto ao processo de ingresso e aceitação do aluno nas repúblicas, segundo os depoimentos das entrevistas realizadas, existe um período de adaptação conhecido como "batalha". Em geral, o calouro ou estudante que deseja morar em uma república federal deve passar por um período de aproximadamente três meses "batalhando vaga". Este prazo pode ser estendido para até seis meses, dependendo do desempenho do aluno calouro.

Os estudantes das repúblicas entrevistadas descreveram atividades comuns destinadas majoritariamente aos calouros e consideram que tais atividades são uma forma de demonstrar se realmente estes novos alunos demonstram e têm interesse em morar na república; zelando pela casa como um patrimônio histórico nacional. Atividades como retirar o lixo produzido por todo o grupo, abrir a casa pela manhã e fechá-la à noite, atender telefone e campainha, fazer café de manhã e/ou à tarde e estar atento aos reparos estruturais que surgirão na casa são algumas tarefas comuns à maioria dos calouros das repúblicas. Como justificativa têm-se a necessidade de realizar tarefas que demonstrem compromisso com horários, zelo pela casa, vontade de aprender as tradições da casa e boa comunicação com os demais moradores e amigos da república.

Após o período de "batalha" o calouro possui uma aprovação ou não para tornar-se morador da república. Todos os moradores votam e para que ocorra a "escolha" deve haver, em maioria, unanimidade dos votos. Se os moradores optarem pela não aceitação do calouro, o "veto", ele deixa a casa e procura outro lugar para morar. Caso o estudante seja aceito, ele passa pela "escolha", uma festa para comemorar e dar boas-vindas ao novo morador.
As festas nas repúblicas universitárias, também conhecidas como "rocks", são corriqueiras dentro do contexto acadêmico. Em se tratando de uma cidade universitária como Ouro Preto, e das relações em rede estabelecidas pelos acadêmicos, tais festas tornam-se referências e servem como fonte de renda para as repúblicas quando estas necessitam de recursos.

Além disso, a própria lógica dos processos de sociação e sociabilidade entre acadêmicos, acaba por selecionar o consumo de bebidas, a "pegação" e o "curtir" como elementos objetivos desses processos de socialização, como apontado por Simmel (1983). O autor aponta que nos processos de sociação dentro de grupos, aspectos objetivos são estabelecidos como parâmetros de identificação com o grupo, a partir de então, apenas aqueles que se identificam e codificam os processos de socialização de forma semelhante se envolvem e são reconhecidos pelo grupo como pertencente (SIMMEL, 1983). Desta forma, a próxima sessão é destinada aos conceitos de Simmel $(1983,2006)$ adotados neste artigo.

\section{Georg Simmel: Algumas Contribuições Para os Estudos em Administração}

Apesar de não estar inserida no campo da Administração, a sociologia de Georg Simmel (1983) é utilizada como lente de análise para diversas áreas. Segundo Chiesa, Kihara (2015) poucos trabalhos no campo da Administração fazem a relação entre Simmel e os Estudos Organizacionais, mas alguns autores consideram os estudos simmelianos uma importante contribuição para a discussão sobre sociabilidade no âmbito das organizações. Fantinel, Cavedon e Fischer (2012), por exemplo, utilizam o conceito de sociabilidade aplicado ao espaço urbano e contemporâneo dos cafés. Contudo, como afirma Waizbort (2007), os estudos de Simmel estiveram por muito tempo subjulgados na academia e apenas após os estudos da Escola de Chicago obtiveram maior destaque. De forma a jogar luzes sobre algumas contribuições 
de Georg Simmel $(1983,2006)$ para os estudos organizacionais, serão apresentados os conceitos utilizados para a análise dos dados.

Para Simmel (1983) a sociedade é constituída por pequenas interações sociais movidas pelos interesses das pessoas. Segundo o autor esses interesses possuem natureza individual e podem ser conscientes ou inconscientes e, a partir do momento que transpassam da esfera da individualidade para a esfera coletiva, a partir de uma interação, geram uma forma social chama por Simmel (1983) de formas de sociação. Segundo o autor os homens vivem com outros homens e agem com, por e contra outros homens de acordo com seus interesses e objetivos. O autor completa que as formas de sociação são mecanismos que corroboram para que o sujeito influencie os outros e seja também influenciado por eles. De acordo com o autor, a sociação pode ser definida como:

[...] a forma (que se realiza de inúmeras maneiras distintas) na qual os indivíduos, em razão dos seus interesses - sensoriais, ideais, momentâneos, duradouros, conscientes, inconscientes, movidos pela causalidade ou teologicamente determinados -, se desenvolvem conjuntamente em direção a uma unidade no seio da qual esses interesses se realizam. (SIMMEL, 2006, p. 60-61)

Os estudos de Simmel (2006) também evidenciam a existência de conteúdos autônomos que, segundo o autor, são aqueles que se desvencilham de seus interesses iniciais, mesmo que não completamente, e passam a existir por si mesmos. Ele analisa a sociabilidade como uma forma lúdica de sociação, como um espaço onde a interação sai da formalidade e passa para o nível da informalidade, da brincadeira e da conversa.

Toda sociabilidade é um símbolo da vida quando esta surge no fluxo de um jogo prazeroso e fácil. Porém, é justamente um símbolo da vida cuja imagem se modifica até o ponto em que a distância em relação à vida o exige. Da mesma maneira, para não se mostrar vazia e mentirosa, a arte mais livre, fantástica e distante da cópia de qualquer realidade se nutre de uma relação profunda e fiel com a realidade. (SIMMEL, 2006, p. 80)

Serão adotados, além dos conceitos de sociação e sociabilidade, os efeitos da subordinação entre superiores e subordinados descritos por Simmel (1983). O autor afirma que sociologicamente existe uma influência recíproca entre os indivíduos e ao mesmo tempo em que o subordinador influencia o subordinado, o primeiro é também influenciado pelo segundo, contrastando com a consideração de uma relação estritamente mecânica. Simmel (1983) acrescenta que o processo de subordinação sofreu alterações no decorrer da história. Segundo o autor, inicialmente as decisões eram tomadas de acordo com as vontades pessoais dos detentores do poder e, gradualmente, esse poder subjetivo deu lugar ao poder objetivo, cujo interesse reside em trabalhar para o bem comum do grupo; neste sentido tanto os superiores quanto os subordinados trabalham por um único propósito.

Embora alguns conceitos de Simmel (1983) tenham sido publicados na década de 1980, suas contribuições ainda são muito pertinentes para o campo da Administração e demais áreas. Portanto, neste artigo, serão utilizados os estudos deste autor como lente teórico-epistemológica.

\section{Relações de Subordinação nas Repúblicas Universitárias}

As repúblicas universitárias emergem, nas cidades universitárias, enquanto espaços de socialização secundária (BERGER; LUCKMANN, 2011) dos novos acadêmicos. Como apontado por Berger e Luckmann (2011), o processo de socialização secundária faz referência direta à constituição dos indivíduos com base em codificações da realidade, referenciais e vivências extrafamiliar. 
Neste sentido, é possível inferir que aos novos moradores de uma república; os "bixos", os veteranos soam como referencial simbólico social. Enquanto indivíduos que abriram as portas da sociedade ouropretana aos "bixos", os veteranos serão os codificadores dos "certos" e "errados".

Logo, ao refletir sobre esses processos de sociação, aos quais Simmel (1983) se refere, temse a porta de acesso às relações estabelecidas entre calouros e veteranos - uma vez que tal relação é pensada a partir do bom convívio entre as partes, dos processos de identificação de afinidades e de aceitação das partes pelos "termos de um contrato social” implícito nas relações internas às repúblicas universitárias.

Pensando nas relações de poder internas às repúblicas universitárias, é preciso pensar a organização hierárquica destas. O que se observa é que as repúblicas estudantis na cidade de Ouro Preto possuem uma estrutura hierárquica incomum às demais do país, tais como as repúblicas das cidades de Campos dos Goytacazes - RJ (BLANC, 2015) e Curitiba (BERLATTO; SALLAS, 2008), que normalmente se formam em virtude do grande contingente de estudantes que as principais Universidades destas cidades abrigam.

Segundo os relatos dos entrevistados, a posição de calouro é conquistada por aqueles que estão acabando de chegar à cidade e são novos na Universidade. Em diversas entrevistas os respondentes ressaltaram que calouro nem sempre é "bixo" e para ser "bixo" o aluno não precisa ser calouro. Segundo os entrevistados, existe a preocupação em torno da diferenciação dos dois termos, uma vez que o termo "bixo" tornou-se pejorativo. Instituiu-se que, assim como acima descrito, calouro faz referência a qualquer pessoa nova na Universidade. Já os "bixos" podem estar em qualquer período e, desde que existam pessoas um período acima, eles serão "bixos" destas pessoas. Um exemplo seria uma pessoa do oitavo período em um curso de dez períodos; ela não é mais caloura porque não está no início do curso, mas sempre será "bixo" das pessoas do nono e décimo períodos e dos formados. Em suma, "bixos" são quaisquer pessoas que estejam abaixo de alguém e calouros são, obrigatoriamente, os novos alunos. Entretanto, como o termo "bixo" é frequentemente relacionado aos novos membros das repúblicas, tal significado será adotado neste artigo por ser mais usual.

Acima dos "bixos" existem os "semibixos", aqueles que, de acordo com a hierarquia das casas, estão um nível acima dos "bixos". São os recém escolhidos, portanto, já são oficialmente moradores da república.

O próximo nível é referente aos moradores intermediários. Não são recém escolhidos nem são os mais velhos da república. Em sequência, os próximos níveis são os "vice decanos" e os “decanos". Os "vice decanos" estão logo abaixo dos "decanos", que são os veteranos, aqueles com maior tempo de casa e, normalmente, em períodos mais avançados.

Acima dos decanos, existem os ex-alunos, eles já foram moradores e ao se formarem "inauguraram um quadrinho" em uma cerimônia que conta as histórias do morador até se tornar ex-aluno. Eles têm "direito" de usufruir da estrutura da casa - são considerados os "maiorais", acima até mesmo dos decanos na hierarquia.

Outros dois termos são utilizados na estrutura das repúblicas universitárias. O primeiro deles faz referência aos homenageados, eles são pessoas que já passaram pela república e tornaram-se grandes amigos, por isso foram homenageados e, assim como os ex-alunos, possuem um "quadrinho" na parede, mas, em relação à tomada de decisões pela casa, geralmente, os homenageados não detêm tanto poder. Por último tem-se os agregados, eles são fazem parte da estrutura hierárquica de poder das repúblicas; não ocupam posição de morador dentro da mesma - podendo ser professor, parente ou amigo dos moradores e que comumente estão presentes na república. 
Dada a estruturação das repúblicas universitárias de Ouro Preto, observa-se um forte arranjo hierárquico já estabelecido dentro destas organizações. Tais relações vão ser tratadas por Simmel (1983) como relações de superordenação e de subordinação; no qual as primeiras irão nortear parte das atividades e da organização das relações e a segunda irá ditar aqueles que darão as cartas e serão detentores de poder nas relações.

Ao fazer uma releitura da proposta teórica de Simmel (1983) relacionando com a situação encontrada nas repúblicas universitárias de Ouro Preto, observa-se que, "muitas vezes achamos que uma pessoa ou uma classe exerce a subordinação em nome de um princípio ideal, ao qual a própria pessoa ou classe supostamente se subordina. Por isso, este princípio parece logicamente anterior à organização social" (SIMMEL, 1983, p. 115). Neste ponto, observa-se que as relações de poder perpetuadas nas organizações repúblicas universitárias permitirão que os novos membros se sujeitem/subordinam aos antigos moradores de forma a pensar a organização e bom funcionamento das repúblicas - que é uma forma de organização social estabelecida anteriormente à sua chegada.

Em se tratando de um processo de adequação e de aprendizado que se dará durante o processo de permanência na casa, os calouros tendem a absorver as ordens e aconselhamentos dos mais velhos, visando em algum momento alcançar experiência e domínio do saber e da prática para ocupar tal posição. Neste sentido, Simmel (1983, p. 115) aponta que "a verdadeira organização da dominação entre as pessoas parece se desenvolver em consequência daquela dependência ideal"; pois, os veteranos tendem a dominar e exercer maior poder sobre os calouros devido a pouca experiência e conhecimento destes sobre a gestão da república.

Outra questão a ser salientada faz referência à possível subversão de valores (e até mesmo identidade) dos "bixos", em busca de um processo de identificação por parte dos veteranos com eles.
Uma vez que os "bixos" precisam ser aprovados nas batalhas e desafios para se tornarem membros permanentes há, portanto, uma busca pela necessidade de identificação com o grupo e viceversa (BERGER; LUCKMANN, 2011, p. 171):

Esse processo (socialização) não é unilateral nem mecanicista. Implica uma dialética entre identificação e autoidentificação, entre a identidade objetivamente atribuída e a identidade subjetivamente apropriada. A dialética, que está presente em cada momento em que o sujeito se identifica com os outros para ele significativos, é, por assim dizer, a particularização na vida individual da dialética geral da sociedade.

Nesse sentido, antes mesmo de pertencer à república, os "bixos" são subordinados "identitariamente" à república que almeja e aos membros a ela vinculados. E, ao refletir sobre o fato dos indivíduos estudantes passarem pela república e nela não permanecem, percebe-se que a questão do poder passa então a revestir o "cargo" ou "posição" dentro da república; não necessariamente os indivíduos. Simmel (1983, p. 115) vai apontar, então, que "através da espiritualização do poder dominador ou através da expansão e despersonalização de toda a relação, desenvolvese gradualmente um poder ideal objetivo acima destas superordenações e subordinações"; logo, o respeito e subordinação encarnam-se nas posições, na manutenção dos quadros aos homenageados, na disposição dos quartos melhores para os veteranos, na divisão de tarefas braçais e intelectuais entre calouros e veteranos, respectivamente.

Dessa forma, reforça-se que são os moradores, especialmente os decanos, e ex-alunos os dotados de podere respeito, sobrando aos demais a subordinação. No entanto, pondera-se que os processos de subordinação nem sempre se referem às situações de opressão, uma vez que, "os diferentes aspectos do poder como: a força e a fraqueza, o controle e 
a dominação e as direções da liderança, incluem ou excluem a constituição de comprometimento" (SOARES; FLECK, 2014, p. 71). Ou seja, a depender das questões "comportamentais" dos calouros e seu nível de comprometimento com as atividades organizacionais, os instrumentos de poder e coerção podem ser deixados de lado.

Assim sendo, ainda que todo este processo de despersonificação do poder dentro das organizações repúblicas universitárias seja tratado, Simmel (1983, p. 115) reforça que "o superior exerce então o seu poder meramente na qualidade do representante mais próximo desta força ideal objetiva"; portanto, sempre haverá um morador mais velho que irá exercer tal poder e orientar as atividades da casa quanto à sua organização, bem como a distribuição de responsabilidades e atividades.

\section{Percurso Metodológico}

Trata-se de um estudo qualitativo, de natureza exploratória, que realizou a apreensão empírica do objeto por meio da triangulação das seguintes técnicas: entrevistas, observação não participante e pesquisa documental. Bansal e Corley (2011) afirmam que a pesquisa qualitativa aproxima o leitor do objeto em estudo, possibilitando o surgimento de novas ideias. Bamberger e Pratt (2010) acrescentam que pesquisas realizadas em contextos pouco explorados ajudam a enriquecer o campo da administração e podem trazer novas perspectivas para a área.

Ao todo foi realizado quatorze entrevistas individuais semi-estruturadas e gravadas na cidade de Ouro Preto, no ano de 2015. Foram executadas entrevistas com estudantes de sete repúblicas federais de Ouro Preto, sendo um veterano(a) e um calouro(a) de cada. As entrevistas foram realizadas com um dos moradores(as) que vivem na república há mais tempo, chamados "decanos(as)" e "vicedecanos(as)", e com um dos candidatos a tornaremse moradores ou moradores recém escolhidos, conhecidos respectivamente como "bixos" e "semibixos". O seguinte roteiro foi seguido: o que é ser "bixo"; como funcionam as batalhas; como é viver em república; como funciona a divisão de tarefas; quais as diferenças percebidas entre aqueles que vivem em repúblicas e os que vivem em apartamento.

Os critérios iniciais de escolha das repúblicas estudantis pesquisadas foram: menores anos de fundação e existência de moradores com significativa diferença de tempo que residam na república. As repúblicas que participaram da pesquisa possuem processos de formação distintos, contribuindo para que suas estruturas também sejam diferentes. As influências no processo de estruturação estão diretamente ligadas ao contexto histórico da época em que as repúblicas foram fundadas, assim como a personalidade e atitudes de seus primeiros moradores. Essa diversidade identificada nas repúblicas ouropretanas contribuiu para tornar o debate mais profícuo e justificar a escolha do locus.

A observação não participante se deu durante os meses de abril e maio de 2015. A pesquisa documental levantou regimentos e estatutos das repúblicas estudantis disponíveis no site da Universidade Federal de Ouro Preto, além do enquadramento jurídico das repúblicas e demais informações disponíveis no site da REFOP. Foram também estudados os processos de seleção, ascensão e sucessório. Os dados coletados foram tratados com base na técnica de análise de conteúdo (BARDIN, 1977).

A análise da pesquisa documental e das entrevistas foi utilizada como embasamento para a verificação da estrutura organizacional das repúblicas de Ouro Preto, para que assim fosse possível a comparação dos dados aqui obtidos com os dados levantados acerca de repúblicas estudantis em outras regiões do Brasil ( BERLATTO; SALLAS, 2008; BLANC, 2015). Desta forma, o próximo item apresenta os dados obtidos na realização da pesquisa e suas análises. 


\section{Análise e Discussão}

As relações de poder nas repúblicas são iniciadas no período de batalha. Os moradores mais baixos na hierarquia ("semibixos") ensinam as tarefas da casa aos "bixos" (que podem ser comparados aos estagiários nas organizações), e supervisionam a execução das tarefas, dedicação com a república e boa convivência com os demais moradores e amigos da casa.

(01) A gente não tem assim uma (hierarquia), na verdade depois dos "bixos" a gente não divide por questão... a gente divide por... por exemplo, vou dar um exemplo: a caixinha e a presidência geralmente são os dois mais velhos. [...] Eu posso te dar assim, uma ordem de responsabilidade por hierarquia, que assim, que eu garanto que quem, que por essa ordem quem tiver mais abaixo é mais novo de casa. Ai vai: mais velho presidência e caixinha [...] (DECANO 1)

No trecho (01) o entrevistado aponta que, ainda que não haja uma formalização da estrutura da república ou, ao menos, uma estrutura rígida sobre as funções ocupadas por cada um dos moradores, as repúblicas universitárias apresentam uma organização mínima para seu funcionamento. Como verificado na segunda seleção lexical, a definição do tipo de atividade que cada membro desenvolve aponta o nível/posição hierárquica ocupada pelo morador. De acordo com os efeitos da subordinação descritos por Simmel (1983) este processo pode representar o poder objetivo, uma vez que embora cada posição da hierarquia possua uma responsabilidade, aqui aqueles que detêm o poder também trabalham em prol da manutenção da república.

Após escolhido, o antes "bixo" e agora morador é nomeado "semibixo" e fica responsável por ensinar, auxiliar e supervisionar as tarefas dos calouros que estão chegando, além de começar a realizar tarefas mais burocráticas da casa. Este processo de aceitação pode ser comparado à promoção do operário, que se esforçou para realizar as tarefas e que a partir de agora está inserido no nível intermediário da organização, sendo responsável pelo planejamento gerencial, como planejamento e controle de como realizar as atividades necessárias, gestão de pessoas e gestão da qualidade.

(02) Então acaba que como diz um morador nosso lá que "uma casa sem "bixo" é uma casa triste" porque acaba que a gente faz desde o trabalho braçal até o trabalho de comunicação, então assim, você aprende bastante [...] Acordar e encher os filtros da casa, repor os papeis higiênicos da casa, na parte da manhã. Na parte da tarde, por volta de cinco e meia, tirar o lixo da casa inteira, reservar o pão pro café da noite, e fazer o café da noite antes das dez horas. A gente reserva cinco e meia pra pegar o pão sete e meia, aí a gente consegue ter um pão mais fresco do que pegar às vezes cinco $\mathrm{e}$ meia da tarde ("BIXO" 1).

No trecho (02) ficam mais claras as funções desenvolvidas pelos "bixos" dentro das repúblicas e a própria interpretação de sua função de "divertir" os moradores mais velhos a partir do desenvolvimento de suas atividades. Baseando na primeira seleção lexical do trecho observa-se que o processo inicial de subordinação dos "bixos" aos moradores torna a relação entre os novos e antigos moradores uma questão de replicação das situações, muitas vezes constrangedoras, vividas quando calouros, pelos hoje veteranos.

As atividades rotineiras e de funcionamento básico da república estendem-se desde o trabalho braçal - atividades tidas como desenvolvidas por domésticas - até o de comunicação - como atividades voltadas ao secretariado e relações públicas. O desenvolvimento destas atividades aponta também o percurso de aprendizado que os novatos passam e que será repassado aos novos moradores quando estes primeiros se tornarem veteranos na casa. 
(03) "Quando a gente é "bixo" ou calouro de uma república a gente passa por um período de adaptação, você não é chamado de morador porque as meninas têm que te conhecer melhor, é muito difícil você colocar uma pessoa estranha na sua casa" ("BIXO"2)

O trecho (03) traz a manobra discursiva do uso do termo "morador" como forma de um reconhecimento simbólico (ou não) do indivíduo enquanto pertencente àquele espaço. A questão do "estranho" na casa, reforça também as condições impostas aos "bixos" e a consequente aceitação destas condições pelos novatos para, então, serem reconhecidos como "dignos" à fazerem parte daquela organização, daquela república. Essa sensação de pertencimento pode ser analisada de acordo com o conceito de "a casa" e "a rua" de DaMatta (1997). Segundo o autor pertencer à casa significa fazer parte de um grupo específico e seleto que agrupa apenas a família a os amigos. A casa representa o local seguro onde ocorrem as relações afetivas, enquanto a rua é caracterizada pela impessoalidade e insegurança (DAMATTA, 1997). Desta forma, pertencer a uma república confere ao novo morador a segurança de estar entre amigos que, como afirmam os moradores das repúblicas, formam uma família.

(04) Ser um "bixo" bom? Seria fazer as coisas com responsabilidade. Tipo, não só fazer tudo no tempo que te pedem, seguir as regras, digamos assim, mas também ter afinidade com as pessoas da casa. A pessoa tem que ter boa convivência porque isso também faz parte de um, digamos, de um "bixo" bom. Você saber ouvir a opinião, você saber ouvir um não, sabe? Ou saber ouvir que você ta errada, saber chegar em um consenso porque grande parte dos problemas de morar junto é exatamente esse, de convivência mesmo, as ideias não baterem e a pessoa ser dificil de lidar ("BIXO"2).

O trecho (04) traz outra manobra discursiva desenvolvida pelos veteranos para validar a subordinação dos "bixos" às suas vontades: o "bixo" bom. Ser um "bixo" bom significa, como apontado na seleção lexical, muito além do que apenas seguir regras e submeter-se às vontades dos moradores veteranos, significa também buscar a boa convivência em um ambiente de submissão e suplantação de ideias e vontades aos interesses dos moradores mais antigos.

O processo de ascensão continua à medida que moradores deixam a casa, seja após a formatura, tornando-se ex-aluno, ou pela decisão de deixar a casa, conhecido como "catar" a república. À medida que moradores da alta hierarquia deixam seus postos, os demais moradores ascendem na ordem em que foram escolhidos. Desta forma, aqueles antes inseridos no nível intermediário da organização farão parte do nível institucional e serão responsáveis pelo planejamento estratégico da casa, definindo o que fazer quanto às finanças, marketing e vendas, como ocorre em festas como o carnaval.

(05) E lá a batalha é assim, as coisas que eu não faço elas pegam e fazem, assim elas não vão ficar me cobrando, aí você vê assim "Nossa, ela fechou a janela hoje, tipo assim, ela que ta aqui mais tempo pegou a minha responsabilidade, entendeu?". Eu não posso deixar prá outra pessoa fazer. Nossa é muito pior do que se tivesse me cobrado sabe, "Fulana, já deu o horário. E a janela fechada?" Elas não cobram isso, elas esperam que você tinha essa responsabilidade ("BIXO"2).

Começar com tarefas que não exijam muito "esforço mental" ou até mesmo consideradas "braçais" pode ser comparado à contratação de funcionário do chão de fábrica, aquele que atua no nível operacional executando as ações planejadas, propondo correções e melhorias e é responsável pelo planejamento operacional da organização. As tarefas serão repetitivas e muitas vezes para o calouro, ou novo operário, as atividades serão vistas 
de forma diferente quanto à importância dentro da organização e para o crescimento pessoal do sujeito.

Após formar, o morador é elevado ao "cargo" de ex-aluno e durante as comemorações de sua formatura, ocorre a "inauguração do quadrinho", momento em que algumas de suas histórias vividas em Ouro Preto e na república serão contadas e uma foto do agora ex-aluno é colocada em um quadrinho na parede e ali ficará todos os dias como um eterno integrante da república. Os ex-alunos podem ser comparados aos Stakeholder. Estes indivíduos se interessam pelo alcance dos objetivos da república, influenciaram e continuarão influenciando na formação desta organização.

\section{Considerações Finais}

Visando atingir o objetivo de analisar as relações de subordinação e poder nas repúblicas universitárias em Ouro Preto, verificou-se que tal objetivo foi atingido ao proporcionar uma reflexão mais ampla sobre os processos de estruturação das repúblicas universitárias, a despersonificação das posições (e cargos) e a consequente manutenção de subordinação dos calouros aos seus veteranos moradores mais antigos da casa.

Outra questão observada com o desenvolvimento do presente trabalho é sobre as repúblicas enquanto organizações estruturadas, com cargos e hierarquias bem definidos. Foi verificada a existência de uma divisão do trabalho bem clara e a separação do trabalho braçal e do trabalho intelectual o que reforça a discussão de subordinação e desproporcionalidade de poder nas relações entre calouros e veteranos.

Aqueles que são moradores há mais tempo, geralmente, exercem atividades que demandam mais confiabilidade, como responsabilidades financeiras das contas mensais da casa, conhecida como presidência; dinheiro guardado para obras e reparos estruturais, chamado caixinha; e quaisquer outras atividades que envolvam o dinheiro da casa, como a associação, o valor arrecadado no carnaval e em outros eventos.

Os calouros ou, quando não houver calouro, moradores recém escolhidos, subordinados aos veteranos, acabam por aceitar as atividades que fazem referência a acordar cedo para pegar pão, limpeza dos quintais das casas, organização do lixo, alimentação dos bichos de estimação, etc. O desenvolvimento de tais atividades acaba sendo repassado entre as gerações de calouros que as repúblicas vão criando, possibilitando assim a perpetuação do funcionamento da república, mas também desta relação assimétrica de poder.

Enquanto possibilidades para se refletir sobre a organização das repúblicas universitárias, abrese aqui uma discussão mais acalorada que pode ser desenvolvida pensando as questões simbólicas desenvolvidas dentro do âmbito das repúblicas para perpetuar os indivíduos (e não só a posição ou cargo).

\section{Referências}

BAMBERGER, P. A.; PRATT, M. G. Moving forward by looking back: reclaiming unconventional research contexts and samples in organizational scholarship. Academy of Management Journal, Champaign, v. 53, n. 4, p. 665-671, 2010.

BANSAL, P.; CORLEY, K. The coming of age for qualitative research: embracing the diversity of qualitativemethods. Academy of Management Journal, Champaign, v. 54, n. 2, p. 233-37, 2011.

BARDIN, L. Análise de conteúdo. Lisboa: Ed. 70, 1977.

BERGER, P. L.; LUCKMANN, T. A construção social da realidade: tratado da sociologia do conhecimento. Tradução de Floriano de Souza Fernandes. 33. ed. Petrópolis: Vozes, 2011.

BERLATTO, F.; SALLAS, A. L. F. Um lar em terra estranha: espaço e sociabilidade em uma casa de estudantes feminina. Revista Chilena de Antropologia Visual, Santiago, v. 2, n. 12, p. 1-17, 2008.

BLANC, M. V. Individualização juvenil: um estudo em trajetória entre (ex) moradores de repúblicas estudantis. Revista Sinais, Vitória, v. 2, n. 18, p. 42-68, 2015. 
CERTEAU, M. A invenção do cotidiano 1: artes de fazer. Petrópolis: Vozes, 1994.

CHIESA, C. D.; KIHARA, S. R. A sociabilidade e a forma de organizar: interpretações Simmelianas em um projeto social. Revista Gestão \& Conexões, Vitória, v. 4, n. 1, p. 187-209, 2015.

DAMATTA, R. A casa \& a rua: espaço, cidadania, mulher e morte no Brasil. 5. ed. Rio de Janeiro: Rocco, 1997.

FANTINEL, L. D.; CAVEDON, N. R.; FISCHER, T. Produção de significações do espaço e sociabilidade em um café artesanal de Salvador. RIGS: Revista Interdisciplinar de Gestão Social, Salvador, v. 1, p. 5174, 2012.

GARRIDO, E. N.; MERCURI, E. N. G. S. A moradia estudantil universitária como tema na produção científica nacional. Psicologia Escolar e Educacional, São Paulo, v. 17, n. 1, p. 87-95, 2013.

MACHADO, O. L. Repúblicas estudantis de Ouro Preto e Mariana: percursos e perspectivas. Frutal: Prospectiva, 2014. (Acta Acadêmica, Edição Especial).
SIMMEL, G. O efeito da subordinação sob o princípio das relações entre superiores e subordinados. In: MORAES FILHO, E. (Org.). Georg Simmel: Sociologia. São Paulo: Ática, 1983. p. 115-121. (Grandes Cientistas Sociais, n. 34).

- Questões fundamentais de sociologia: indivíduo e sociedade. Rio de Janeiro: Zahar, 2006.

SOARES, L.; FLECK, C. F. Consequências das relações entre gestor e subordinado para o comprometimento organizacional: um estudo em uma empresa familiar. Revista Organizações em Contexto, São Bernardo do Campo, v. 10, n. 20, p. 59-84, 2014.

UNIVERSIDADE FEDERAL DE OURO PRETO UFOP. Resolução CUNI $n^{\circ}$ 779. Disponível em: <http:// www.ufop.br/downloads/resolucao_cuni_779.pdf $>$. Acesso em: 13 ago. 2015.

WAIZBORT, L. Simmel no Brasil. Dados: Revista de Ciências Sociais, Rio de Janeiro, v. 50, n. 1, p. 11-48, 2007. 
